\title{
Frecuencia de rinitis atrófica $y$ grado de lesión de los cornetes nasales de cerdos en Yucatán, México.
}

Artículo Original

Marco A. Torres-León, José de Jesús Williams, Francisco J. Castro-Aguilar, María del R. SalazarFajardo.

Facultad de Medicina Veterinaria y Zootecnia. Universidad Autónoma de Yucatán. Mérida, Yucatán, México.

\section{RESUMEN.}

Introducción.- El complejo respiratorio de los cerdos es uno de los principales síndromes que afectan a la industria porcina, debido al efecto negativo que tiene sobre los costos de producción por concepto de mortalidad, tratamientos, disminución en la ganancia diaria de peso y aumento en la conversión alimenticia. El objetivo de este estudio fue determinar la frecuencia de las lesiones macroscópicas en cornetes de cerdos finalizados obtenidos en el mercado municipal No. 32 de Mérida, Yucatán, México.

Materiales y Métodos.- Se inspeccionaron 101 hocicos de cerdos de engorda finalizados adquiridos en el mercado municipal No. 32 de Mérida, Yucatán, México, de abril a junio de 1997. Con un rinómetro se determinó el grado de rinitis. A los casos positivos a rinitis atrófica progresiva (RAP) se les realizó un análisis histopatológico y bacteriológico.
Resultados.- Cincuenta y cinco $(54.5 \%)$ hocicos presentaron RAP. Treinta y tres $(60.0 \%)$ cornetes nasales presentaron grado $2,17(30.9 \%)$ cornetes nasales con grado 3 y $5(9.1 \%)$ cornetes nasales con grado 4. Se observó 1 (1.8\%) caso con cuerpos de inclusión y correspondió al grado 4 de RAP. Se aislaron Pasteurella multocida en 2 (3.6\%) casos positivos a RAP y correspondieron a los grados 2 y 4 y Bordetella bronchiseptica en 3 (5.5\%) muestras y correspondieron a los grados 2, 3 y 4 de RAP.

Discusión.- Las diferencias encontradas entre la RAP de este estudio y las reportadas por los diferentes autores, probablemente se debieron a la técnica utilizada. La baja frecuencia de aislamientos probablemente se debió a que las muestras fueron tomaron de cerdos sacrificados en el rastro, lo cual pudo favorecer la contaminación de las muestras. La RAP probablemente se asocia a los agentes etiológicos B bronchiseptica, $P$ multocida y

Solicitud de sobretiros: M. en C. José de J. Williams, Depto. de Epidemiología y Salud Pública, Facultad de Medicina Veterinaria y Zootecnia. Universidad Autónoma de Yucatán, Apdo. Postal 4-116. Itzimná. CP. 97100. Mérida, Yucatán, México. Tel.: (9) 942-3200 Fax: (9) 942-3205

E-mail: jwill@tunku.uady.mx

Recibido el 22/Julio/1999. Aceptado para publicación el 4/Oct./1999. 


\section{MA Torres-León, J de J Williams, FJ Castro-Aguilar, M del R Salazar-Fajardo.}

Citomegalovirus. En el estado de Yucatán, México, este es el primer reporte de un caso de rinitis atrófica con cuerpos de inclusión. Esto permite demostrar que la RAP es un padecimiento que no necesariamente guarda relación con un solo agente etiológico. (Rev Biomed 2000; 11:99-105)

Palabras clave: Cornetes nasales, rinitis atrófica progresiva, cuerpos de inclusión, Citomegalovirus.

\section{SUMMARY.}

Frequency of atrophic rinitis and grade lesions in pig nasal turbinates in Yucatan, Mexico. Introduction.- The respiratory complex in pigs is one of the most important syndromes in the pig industry. Mortality, low weight gain, low food conversion and cost of treatments, are the most important effects in the pig industry. The objective of the present study was to determine the frequency of snout macroscopy lesions in fattening pigs from the municipal market (No. 32) of Merida, Yucatan, Mexico.

Material and Methods.- A hundred and one fattening pig snouts from the municipal market of Merida, Yucatan, Mexico (No. 32) were inspected from April to June 1997. The degree of rinitis was evaluated using a rinometry. Histopathology and bacteriology exams were carried out on the positive cases of progressive atrophic rinitis (PAR).

Results.- Fifty five snouts showed PAR (54.5\%). Thirty three nasal turbinates $(60.0 \%)$ showed grade 2, $17(30.9 \%)$ grade 3 and $5(9.1 \% 9)$ grade 4. Inclusion bodies were found in one case $1(1.8 \%)$ with grade 4 of PAR. In 2 cases of PAR, Pasteurella multocida was isolated, corresponding to 2 and 4 grade. In 3 samples (5.5\%) Bordetella bronchiseptica was isolated, corresponding to 2, 3 and 4 of RAP.

Discusion.- The differences of PAR found in the present study and those reported by other authors were probably due to the type of test used in the studies. The low frequency of agent isolation was probably due to samples being taken in the slaughterhouse where there is a high risk of contamination. The PAR were probably associated with $B$ bronchiseptica, $P$ multocida and Citomegalovirus. It is the first report of PAR with inclusion bodies in Yucatan state. This result shows that PAR is not associated with only one etiologic agent. (Rev Biomed 2000; 11:99-105)

Key words: Nasal turbinates, progressive atrophic rinitis, inclusion bodies, Citomegalovirus.

\section{INTRODUCCIÓN.}

El complejo respiratorio de los cerdos sigue siendo una de las principales preocupaciones en la industria porcina, nacional e internacional, debido al efecto negativo que tiene sobre los costos de producción por concepto de mortalidad, tratamientos, disminución en la ganancia diaria de peso y aumento en la conversión alimenticia (1).

En México el complejo respiratorio se encuentra asociado a la presencia de organismos patógenos como bacterias, mycoplasmas y virus. El efecto negativo de estos agentes en la producción porcina se ve potencializado cuando interaccionan con diferentes factores como el sistema de producción, manejo, medio ambiente y nutrición. La rinitis atrófica progresiva (RAP) es una enfermedad del complejo respiratorio que afecta la parte superior del aparato respiratorio porcino, y puede producir atrofia de los cornetes, desviación del septo nasal y deformaciones de los huesos de la nariz (2). En México el problema existe desde hace algunos años y se cree que la importación de animales para pie de cría fue la causa de la introducción de la enfermedad al país. La RAP, es una enfermedad donde pueden interactuar Bordetella bronchiseptica y Pasteurella multocida serotipos A y D (2); además se ha asociado a otros agentes, tal es el caso de la rinitis con cuerpos de inclusión causado por un citomegalovirus (3).

En el estado de Yucatán, México, no se conoce ningún reporte sobre la frecuencia de esta

\section{Revista Biomédica}


Rinitis atrófica en cerdos.

enfermedad; por lo tanto el objetivo del presente trabajo es determinar la frecuencia de las lesiones macroscópicas en cornetes de cerdos finalizados obtenidos en el mercado municipal No. 32 sacrificados en el rastro municipal de Mérida, capital del estado de Yucatán.

\section{MATERIALES Y MÉTODOS.}

Se inspeccionaron 101 hocicos de cerdos de engorda finalizados adquiridos en el mercado municipal No. 32 de Mérida, Yucatán, México, de abril a junio de 1997. Los hocicos fueron conservados en refrigeración a $4^{\circ} \mathrm{C}$ y trasladados a los laboratorios de patología y bacteriología de la Facultad de Medicina Veterinaria y Zootecnia de la Universidad Autónoma de Yucatán.

\section{Evaluación de los cornetes.}

Se realizó un corte transversal entre el primero y segundo premolar con una sierra manual de dientes pequeños con el fin de no lesionar los cornetes nasales. Posteriormente se utilizó un rinómetro Tylan-ELANCO con escalas en milímetros que determinan el grado de rinitis atrófica. El espacio que se midió fue entre el cornete ventral y el piso de la cavidad nasal de ambos lados de la nariz (4).

\section{Determinación del grado de rinitis atrófica progresiva.}

El grado de RAP se determinó de acuerdo al cuadro 1. Las muestras que tuvieron algún grado de lesión y además presentaron asimetría de los cornetes y/o desviación del septo, se le adicionó medio punto. Asimismo, se evaluó la presencia de exudado purulento. Se consideró como positivo a RAP todas las muestras que presentaron desde el grado 2 hasta el grado 5 (5).

\section{Histopatología.}

Se extrajeron los cornetes nasales de los casos positivos a RAP, los cuales se colocaron en formol buferado al $10 \%$ durante 24 horas para su fijación; posteriormente, las muestras se cortaron

Cuadro 1

Criterios para determinar el grado de lesión de rinitis atrófica progresiva.*

\begin{tabular}{|c|c|c|c|}
\hline $\begin{array}{l}\text { Espacio de los } \\
\text { cornetes nasales } \\
\quad(\mathbf{m m})\end{array}$ & Grado & Interpretación & Descripción \\
\hline 0 a 2 & -1 & Negativo & $\begin{array}{l}\text { Estructura anatómica sin cambios patológicos } \\
\text { aparentes. }\end{array}$ \\
\hline 3 a 6 & 0 & Normal & $\begin{array}{l}\text { Los cornetes llenan la cavidad nasal. Septo en } \\
\text { posición simétrica y derecho. }\end{array}$ \\
\hline 7 a 9 & 1 & Negativo & $\begin{array}{l}\text { Ligera atrofia, morfología anormal del cornete } \\
\text { ventral. }\end{array}$ \\
\hline 10 a 12 & 2 & Sospechoso & $\begin{array}{l}\text { Atrofia leve de uno o ambos cornetes } \\
\text { ventrales con cornetes dorsales normales o } \\
\text { con ligera atrofia. }\end{array}$ \\
\hline 13 a 16 & 3 & Atrofia Moderada & $\begin{array}{l}\text { Moderada atrofia en cornetes ventrales, } \\
\text { usualmente involucrados los cornetes } \\
\text { dorsales. }\end{array}$ \\
\hline 17 a 20 & 4 & Atrofia Marcada & $\begin{array}{l}\text { Atrofia marcada de cornetes dorsales y } \\
\text { ventrales, sustitución fibrosa de cornetes } \\
\text { ventrales. }\end{array}$ \\
\hline 21 o más & 5 & Atrofia Severa & $\begin{array}{l}\text { Pérdida completa de cornetes (solo vestigios) } \\
\text { y/o atrofia de cornetes dorsales. }\end{array}$ \\
\hline
\end{tabular}

* De acuerdo a Straw (5). 
MA Torres-León, J de J Williams, FJ Castro-Aguilar, M del R Salazar-Fajardo.

en pequeñas porciones de tejido $(1 \mathrm{a} 2 \mathrm{cc})$ y se les aplicó la técnica de inclusión en parafina y tinción con Hematoxilina y Eosina (H-E) (6) para su observación al microscopio.

\section{Bacteriología.}

Los cornetes positivos a RAP se lavaron 3 veces con solución salina al $0.85 \%$, se introdujeron hisopos estériles en los cornetes lesionados. Cada hisopo se inoculó en los medios D20 (Agar MacConkey Bioxon con dextrosa al $1 \%$ y furaltadona $20 \mu \mathrm{g} / \mathrm{mL}$ de medio), Base Agar (Bioxon) con sangre de carnero al 5\% (7). Las colonias fueron identificadas de acuerdo a sus características morfológicas $(8,9)$ y pruebas bioquímicas de urea (Bioxon), agar triple azucar (Bioxon), agar de citrato de Simmons (BBL), agar de hierro y lisina (Bioxon), oxidasa y catalasa (8).

\section{Análisis de datos.}

Los datos obtenidos se capturaron y analizaron en el programa Epi-Info 6.02 (10).

Para determinar la frecuencia de las lesiones de RAP se utilizo la siguiente formula (11):

Frecuencia de RAP $=\frac{\text { Número de cornetes positivos a RAP }}{\text { Número total de cometes inspeccionados }} \times 100$

Se utilizó la fórmula anterior para determinar la frecuencia por grado de lesión de los cornetes.

\section{RESULTADOS.}

Cincuenta y cinco $(54.5 \%)$ hocicos presentaron RAP. Treinta y tres (60.0\%) cornetes nasales presentaron grado 2 de RAP (cuadro 2). En las figuras 1 y 2 se presentan los casos de cornetes de cerdo normal (grado 0) y de cerdo negativo (grado 1), respectivamente. En las figuras 3,4 , y 5 se presentan algunos de los casos positivos a RAP que correspondieron a los grados 2, 3 y 4 respectivamente.

Al examen histopatológico se observó 1 (1.8\%) caso con cuerpos de inclusión y correspondió al

\section{Revista Biomédica}

Cuadro 2

Grado de lesión, frecuencia y porcentaje de rinitis atrófica progresiva en 55 hocicos de cerdos de engorda provenientes del mercado municipal No. 32 de Mérida, Yucatán, México.

\begin{tabular}{ccc}
\hline $\begin{array}{l}\text { Grado de lesión } \\
\text { de rinitis atrófica } \\
\text { progresiva }\end{array}$ & Frecuencia & Porcentaje \\
\hline 2 & 33 & 60.0 \\
3 & 17 & 30.9 \\
4 & 5 & 9.1 \\
Total & 55 & 100.0 \\
\hline
\end{tabular}

grado 4 de RAP.

En los resultados bacteriológicos, se observó $2(3.6 \%)$ casos positivos a $P$ multocida que correspondieron a los grados 2 y 4 de RAP. $B$ bronchiseptica se aisló en $3(5.5 \%)$ muestras que correspondieron a los grados 2,3 y 4 .

\section{DISCUSIÓN.}

La RAP es una enfermedad distribuida mundialmente que afecta a los cerdos de casi todos los países en los que se crían cerdos en condiciones intensivas (12,13). Esto concuerda con los resultados obtenidos en el presente trabajo ya que se encontró una frecuencia de $54.5 \%$ de RAP. En

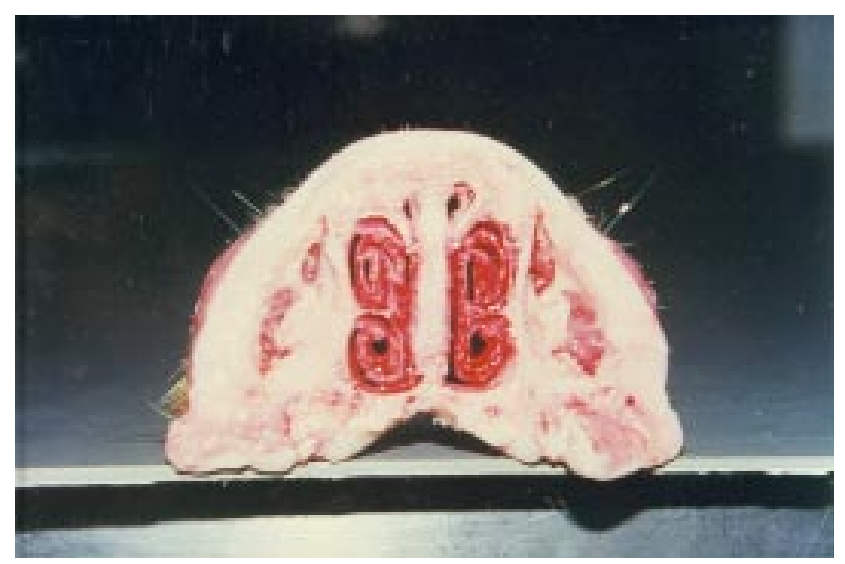

Figura 1.- Corte transversal del hocico de un cerdo sano (grado 0), donde se puede observar la anatomia normal de los cornetes que llenan la cavidad nasal, el septo en posición simétrica y derecho. 


\section{Rinitis atrófica en cerdos.}

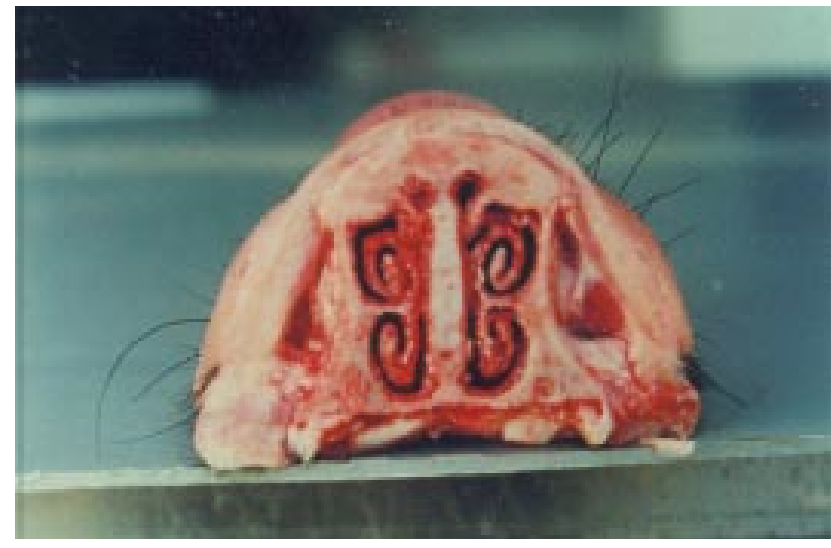

Figura 2.- Corte transversal del hocico de un cerdo negativo a rinitis atrófica progresiva (grado 1), muestra ligera atrofia o morfología anormal del cornete ventral (atrofia escasa).

algunos países productores de cerdos que han estudiado la incidencia de la RAP, han obtenido resultados más elevados, como es el caso de los laboratorios Elanco (14) en Estados Unidos de Norteamérica donde utilizando la técnica del corte transversal del hocico entre el primero y segundo premolar y la medición de la atrofia de los cornetes, evaluaron en diferentes rastros del país 10,356 cornetes de cerdos y encontraron que 7,155 $(69.1 \%)$ cornetes presentaron algún grado de lesión por RAP. En Inglaterra de 2,071 cornetes de cerdos inspeccionados, $1576(75.7 \%)$ resultaron positivos a RAP(15).

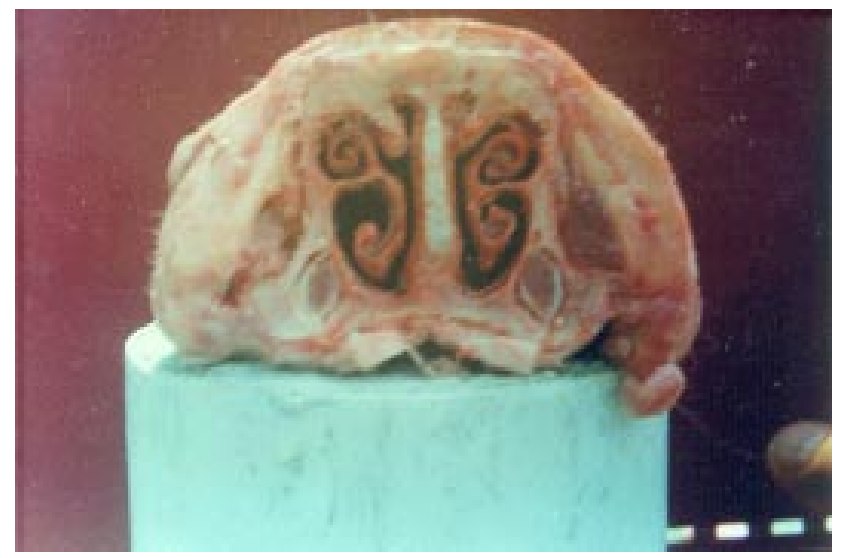

Figura 4.- Corte transversal del hocico de un cerdo que presenta rinitis atrófica progresiva (grado 3), donde se observa atrofia de ambos cornetes ventrales.

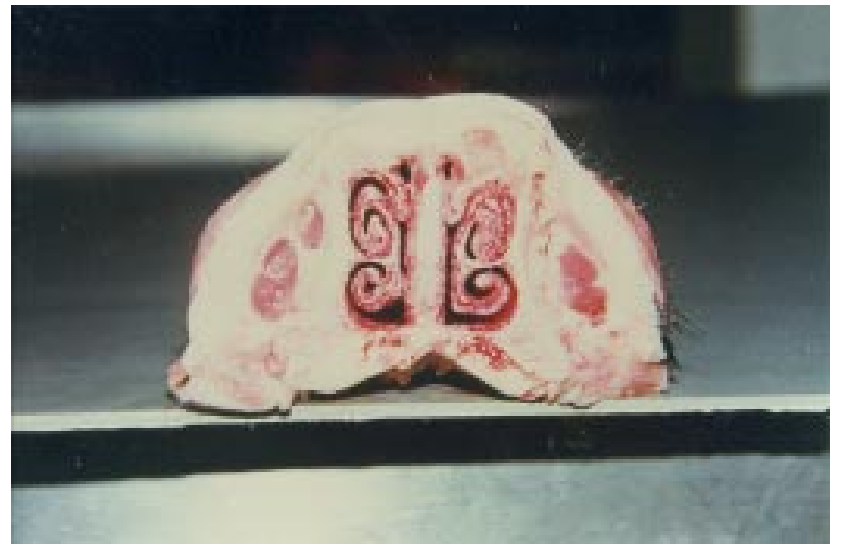

Figura 3.- Corte transversal del hocico de un cerdo que presenta rinitis atrófica progresiva (grado 2), se observa atrofia de uno de los cornetes ventrales y ligera degeneración en los dorsales.

Por otro lado, también hay estudios que reportan incidencias bajas de RAP en comparación a los resultados de este estudio; tal es el caso, de un estudio que se realizó en Nueva Zelanda, donde utilizando el método de corte entre el primero y segundo premolar y otorgando valores en la escala del 0 al 5, examinaron 534 cornetes de cerdo y encontraron que $165(31.0 \%)$ resultaron positivos a RAP (2). Así mismo, Cowart y col. (16) inspeccionaron 85 cornetes de cerdos para medir el grado de RAP y reportaron que 35 (41.1\%) cornetes nasales fueron positivos a RAP. En un

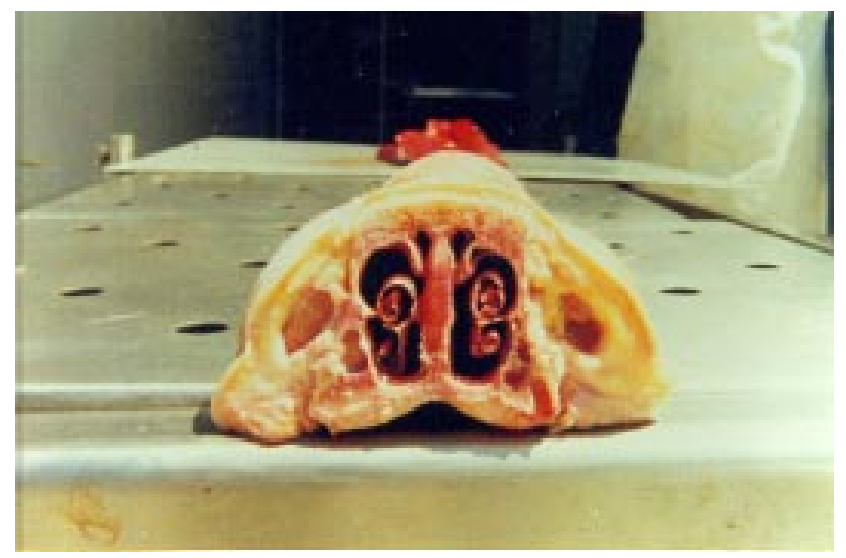

Figura 5.- Corte transversal del hocico de un cerdo que presenta rinitis atrófica progresiva (grado 4), donde se observa atrofia de uno de los cornetes ventrales y ligera degeneración en los ventrales y dorsales.

Vol. 11/No. 2/Abril-Junio, 2000 


\section{MA Torres-León, J de J Williams, FJ Castro-Aguilar, M del R Salazar-Fajardo.}

estudio realizado en México, se reporta que de 5000 cornetes nasales de cerdo inspeccionados provenientes de rastros de varias partes de la República Mexicana, 1270 (25.4\%) se diagnosticaron positivos a RAP (17). El reporte de resultados menores al de este trabajo probablemente se deba a la técnica que utilizaron los autores, la cual se basó en la observación macroscópica de las lesiones en los cornetes nasales de los cerdos, sin hacer una valoración precisa del grado de atrofia a través de la medición del espacio entre el cornete ventral y el piso de la cavidad nasal (5). Lo anterior pudo provocar que casos positivos a RAP, se diagnosticaran como negativos. Sin embargo, de acuerdo a los resultados obtenidos y las diferencias encontradas entre los diferentes estudios, para realizar cualquier estudio y su posterior análisis se debe de considerar los diferentes factores (genética, tipo de alojamiento, alimentación, sistema de producción, ambiente, y programas de prevención y control de enfermedades) que pueden influir en el desarrollo y manifestación de la RAP (18).

En los estudios histológicos se observó un caso de RAP con cuerpos de inclusión. Los cuerpos de inclusión se relacionan con citomegalovirus (3). En México se reportó por primera vez un caso de RAP con cuerpos de inclusión en un lote de cerdos de 3 meses de edad con historia clínica de rinitis atrófica. Los exámenes bacteriológicos resultaron negativos para $B$ bronchiseptica y $P$ multocida (3). En Yucatán, este es el primer reporte de rinitis atrófica con cuerpos de inclusión.

En lo referente a los aislamientos bacteriológicos, existen en México algunos trabajos realizados con el objeto de determinar que agentes son los que están presenten en RAP. López y col. (19) reportaron que de un total de 781 muestras de hisopos nasales, en 103 (13.2 $\%)$ se aisló $P$ multocida tipo A y D, y en 112 (14.3\%) muestras se aisló $B$ bronchiseptica. En lo que respecta al presente trabajo, la frecuencia de aislamientos fue baja ya que en $3(5.4 \%)$ muestras se aislaron $B$ bronchiseptica y en dos (3.6\%) P multocida. La baja frecuencia de aislamiento, se pudo deber a que las muestras se tomaron de cerdos sacrificados en el rastro y para obtener mejores resultados en el cultivo bacteriano, las muestras de hisopos nasales deben de ser de cerdos vivos o durante la necropsia. Sin embargo, si las muestras son obtenidas en rastro, éstas deben de ser de cerdos que no hayan sido sumergido en el tanque de agua caliente ya que son inadecuadas para el aislamiento bacteriológico $(2,7,19)$. Por otro lado, de las muestras obtenidas de tonsilas se tiene una mayor probabilidad de encontrar P multocida $(17,20)$. En nuestro trabajo no fue posible obtener muestras de tonsilas ya que algunas cabezas de cerdos no contaban con ellas o estaban contaminadas.

En conclusión, la RAP estuvo presente en el $54.5 \%$ de las muestras evaluadas y probablemente se asocia a los agentes etiológicos $B$ bronchiseptica, P multocida y Citomegalovirus.

El reporte de un caso de rinitis atrófica con cuerpos de inclusión encontrado en este trabajo puede ser un hallazgo importante, debido a que esta enfermedad generalmente se presenta en cerdos jóvenes. Esto permite demostrar que la RAP es un padecimiento que no necesariamente guarda relación con un solo agente etiológico, de ahí que actualmente se le conozca como un síndrome y no como una entidad patológica definida.

\section{REFERENCIAS.}

1.- Monroy MA, Doporto D, Zuñiga H, Trujillo ME. Evaluación en rastros: Herramienta útil para controlar enfermedades (primera parte). Tecnología Avipecuaria 1994; 11-18.

2.- De Jong MF. (Progresive) Atrophic rhinitis. En: Leman A, Straw B, Mengeling W, D’Allaire S. Taylor D, ed. Disease of swine. $7^{\mathrm{a}}$ ed. Ames, Iowa: University press; 1992. p. 414-35.

3.- Márquez M. Trigo T, Monroy J. Informe de un caso de rinitis con cuerpos de inclusión. Vet Méx 1986; 17:199201.

\section{Revista Biomédica}




\section{Rinitis atrófica en cerdos.}

4.- Christensen N, Cullinane LC. Monitoring the health of pigs in New Zealand abattoirs. New Zealand Vet J 1990; 38:136-41.

5.- Straw BE. Slaugther check metodology. Animal Association of Swine Practitioner 1986; 35-40.

6.- Luna LG. Manual of histopatologic stainining methods of the Armed Forces Institute of Pathology. $3^{\mathrm{a}}$ ed. Edit. New York: McGraw Hill; 1968. p. 31-4.

7.- Smith IM, Baskerville AJ. A selective medium facilitating the isolation recognition of Bordetella bronchiseptica. in pigs. Res Vet Sci 1979; 27:187-92.

8.- Lariviere S, Leblanc L, Mittal KR, Martineau G. Comparason of isolation methods for the recovery of Bordetella bronchiseptica and Pastereulla multocida from the nasal cavities of piglets. J Clin Microb 1993; 31:363-7.

9.- Echeverría P, Salazar R. Manual de bacteriología veterinaria. Mérida: Universidad Autónoma de Yucatán, México; 1995. p. 31-2.

10.- Dean J, Coloubier D, Smith D, Drendell K, Arner T, Dean A. Epiinfo. A word processing database and statistics program for public health (computer program) version 6.02. Center for Disease Control and Prevention (CDC) U.S.A. World Health Organization Geneva, Switzerland; 1994.

11.- Thrusfield M. Epidemiología veterinaria. Madrid: Acribia; 1990. p.339.

12.-Ramírez N, Pijoan A. Diagnóstico de la enfermedades del cerdo. México: Diana; 1982. p. 521-5.

13.- Taylor D J. Enfermedades del cerdo. México: Manual Moderno; 1987. p. 137-41.

14.- Elanco Products Company. Trac Clinics: total respiratory analisis and control. Indianapolis: Elanco Products Company; 1984.

15.- Penny R, Mullen P. Atrophic rhinitis of pigs. Abattoir studies. Vet Rec 1975; 96:518-21.

16.- Cowart RP, Lipsey RJ, Hedrick HB. Measurement of conchal atrophy and pnemonic lesions and their association with growth rate in commingled feeder pigs. JAVMA 1990; 196:1262-4.

17.- Korenfeld KL. Observaciones de la frecuencia de rinitis atrófica porcina en diverso rastros del Distrito Federal y el
Estado de México. Tesis de Licenciatura. Facultad de Medicina Veterinaria y Zootecnia, Universidad Nacional Autónoma de México; 1977.

18.- Monroy MA, Doporto D, Zuñiga H, Trujillo ME. Evaluación en rastros: herramienta útil para controlar enfermedades (segunda parte). Tecnología Avipecuaria 1994; 21-7.

19.-López M, Mercadillo A, Galván E, Ramírez G, Jimémez E, Haro M. Frecuencia de aislamientos de Pasteurella multocida A y D, y Bordetella bronchiseptica a partir de hisopos nasales de 1986 a 1992. Memorias del XXVIII Congreso de la Asociación de Médicos Veterinarios Especialistas en Cerdos; Cancún, México. Septiembre 15-18, 1993. p. 234-6.

20.- Ackermann MR, Register KB. Rinitis Atrófica. Pigs Misset. Especial de.enfermedades respiratorias de los cerdos. 1995; septiembre. p. 24-5. 